\title{
Model-Based Double Closed-Loop Coordinated Control Strategy for the Electro-Mechanical Transmission System of Heavy Power-Split HEVs
}

\author{
Weida Wang ${ }^{1,2} \cdot$ Yuhang Zhang ${ }^{1,2} \cdot$ Xiaoxia Sun $^{3} \cdot$ Changle Xiang $^{1,2} \cdot$ Chao Yang $^{1}$
}

Received: 4 May 2020 / Accepted: 3 December 2020 / Published online: 7 January 2021

(c) The Author(s) 2021

\begin{abstract}
The dual-mode electro-mechanical transmission (EMT) system is a crucial part of power-split hybrid electric vehicles (HEVs), especially for the heavy HEVs. To improve the precision of the system power distribution and the response speed of the electric power supply, a model-based double closed-loop coordinated control strategy is proposed. As the basis of the proposed control strategy, an EMT system model, particularly of an electrical system, is established first. The proposed control strategy includes the power distribution strategy, battery power closed-loop feedback control strategy, and motor coordinated control strategy. To verify the feasibility of the proposed control strategy, simulation and experiment are performed. The results indicate that the proposed control strategy can realize the expected power distribution by coordinating generators and motors and achieve rapid and stable electric power supply.
\end{abstract}

Keywords Hybrid electric vehicles · Electro-mechanical transmission system $\cdot$ Hybrid power-split $\cdot$ Power coordinated control $\cdot$ Multi-power distribution

$\begin{array}{ll}\text { Abbreviations } \\ \text { DC } & \text { Direct current } \\ \text { EMT } & \text { Electro-mechanical transmission } \\ \text { HEVs } & \text { Hybrid electric vehicles } \\ \text { ICE } & \text { Internal combustion engine } \\ \text { M/Gs } & \text { Motors/generators } \\ \text { PID } & \text { Proportional integral differential } \\ \text { PGS } & \text { Planetary gear set } \\ \text { SOC } & \text { State of charge }\end{array}$

Weida Wang

wangwd0430@163.com

1 School of Mechanical Engineering, Beijing Institute of Technology, Beijing 100081, China

2 Beijing Institute of Technology Chongqing Innovation Center, Chongqing 401120, China

3 China North Vehicle Research Institute, Beijing 100072, China

\section{Introduction}

The dual-mode electro-mechanical transmission (EMT) system is an important part of power-split hybrid electric vehicles (HEVs) [1]. By the operation mode switch of the power coupling mechanism, the speed of two motors is altered, and different ratios are realized without adjusting the rotational speed input. The power-split HEVs with dual-mode EMT system have the advantages of a wide speed range and high driving power, which can meet the power demand of auxiliary and specific functional systems and reduce the power requirement of motors $[2,3]$. Therefore, the powersplit HEVs are prospective in future application.

Recently, the power-split HEVs, especially heavy power-split HEVs, have been widely studied owing to their unique advantages. However, there are three key problems to be addressed for power-split HEVs [4-6]: improving the accuracy of power distribution among different power sources, increasing the response speed of the transmission system, and reducing the system fluctuation due to the internal combustion engine (ICE). To solve these problems, much research has been performed. For example, many control methods are proposed to optimize the power distribution [7, 8]. Anselma et al. [9] developed a machine learning logic based on supervised learning 
to get the optimal power-split. Fan et al. [10] proposed an efficiency-based evaluation real-time control strategy to obtain near-optimal fuel economy, which is validated using a mull-mode power-split hybrid track-type dozer. To improve the response speed, Wang and Sun[11] designed a multivariable hybrid powertrain controller. In addition, there are also many scholars are devoted to reducing the system fluctuation. Syed et al. [12] proposed a fuzzy gain-scheduling proportional-integral control algorithm to design an active damping wheel-torque control system. This control system can suppress the driveline oscillations. Zhang et al. [13] used the electric motors as actuators and designed an active vibration controller based on the filtered-x least mean square algorithm.

The coordinated control strategy is an effective method among abundant control methods for the power-split HEVs $[14,15]$. For example, to reduce the system fluctuation, Wang et al. [16] designed a mode transition coordinated control strategy. Zuo et al. [17] adopted a coordinated control algorithm to achieve the torque distribution and compensation, which effectively reduce the torque fluctuation. Sun et al. [18] proposed a torque coordination control strategy using the data-driven predictive control method. This control strategy can achieve faster response and smaller power loss. However, although many researchers adopted this method, they usually only focused on a certain problem, ignoring the complex coupling relationship among the three key issues.

In this paper, an EMT system model is built first, which includes the engine model, battery model, and motor/generator model. Then, a double closed-loop coordinated control strategy is proposed. The strategy consists of the following parts: power distribution strategy, battery power closed-loop feedback control strategy, and motor coordinated control strategy. A rule-based control strategy is used for the power distribution, which determines the steady-state target values. The battery power closed-loop feedback control strategy takes advantage of the high precision and fast response of the motor to compensate for the slow response of the engine. The fuzzy proportional integral differential (PID) is used to adjust the parameters in real time. Lastly, the motor coordinated control strategy based on the fuzzy PID algorithm is used to help the system realize a rapid and stable electric power supply. It is also a closed-loop control strategy. The simulation and test results prove that the proposed control strategy can improve the precision of system power distribution and the response speed of the electric power supply.

The remainder of this paper is organized as follows: In Sect. 2, the EMT system model is built. In Sect. 3, the double closed-loop coordinated control strategy is proposed. In Sects. 4 and 5, the simulation results based on MATLAB/ Simulink and the test results are illustrated, respectively. In Sect. 6, the conclusion is given.

\section{Modeling of the EMT System}

Figure 1 shows the structure of the dual-mode EMT, which consists of one engine, two motors/generators (M/Gs), three planetary gear sets (PGSs), one clutch, one brake, battery packs, and other electric devices [19]. The engine power flows into the coupling mechanism through the planetary carrier of PGS-K2. When the brake is engaged and the clutch is disengaged, M/G A works as a generator, and M/G B acts as a motor. One part of the engine power is delivered to the wheel, and the other part drives $\mathrm{M} / \mathrm{G}$ A to provide electric power to $\mathrm{M} / \mathrm{G} \mathrm{B}$ and other electric devices. This case is defined as the EVT1 mode. While the clutch is engaged and the brake is disengaged, the working states of $\mathrm{M} / \mathrm{G} A$ and $\mathrm{M} / \mathrm{G}$ B swapped. In this case, the EMT is operated in the EVT2 mode.

\subsection{Modeling of the Engine}

The engine model has two types: mechanism model and experimental model. Compared with the experimental model, the mechanism model is too complex to compute, and some parameters of the model are hard to get. Therefore, based on collected experimental data, the experimental model considering the power supply delay is built to simulate the dynamic characteristics of the engine. It is simplified to a first-order transfer function as follows:

$$
\begin{aligned}
& T_{\text {e_act }}=\frac{1}{\tau_{\mathrm{e}} s+1} T_{\mathrm{e} \_ \text {com }} \\
& T_{\mathrm{e} \_ \text {com }}=f\left(n_{\mathrm{e}}, \alpha\right)
\end{aligned}
$$

where $T_{\text {e_act }}$ is the actual engine output torque; $T_{\text {e_com }}$ is the command engine torque; $\tau_{\mathrm{e}}$ is the time constant of the

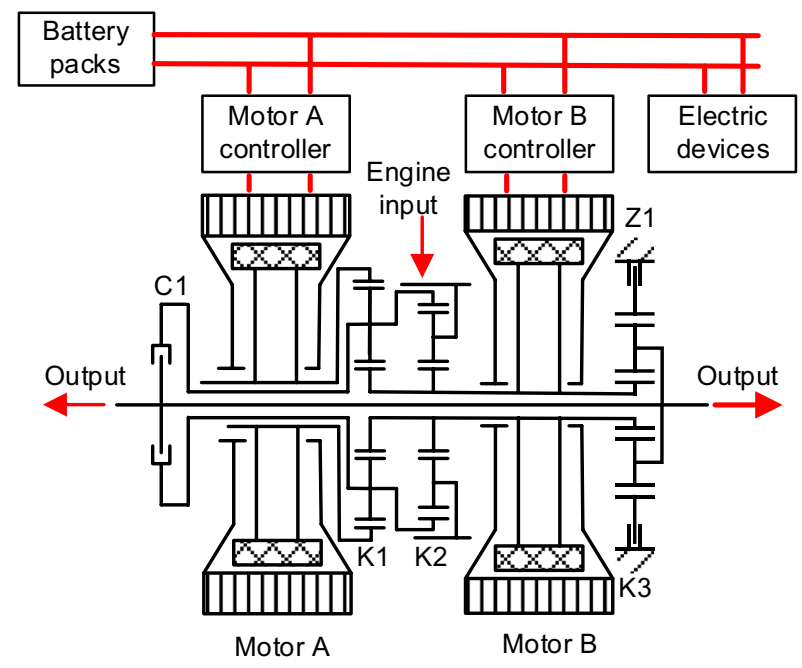

Fig. 1 Structure of the dual-mode EMT [19] 
first-order transfer function that reflects the response of the engine, which is determined by the experimental data; $\alpha$ is the throttle opening; $n_{\mathrm{e}}$ is the engine speed; $f$ represents a function describing the interrelation between the engine characteristics.

\subsection{Modeling of the Battery}

The battery is described by a resistance model, which consists of a variable voltage source and a variable resistance. The equivalent circuit of the battery is shown in Fig. 2.

$U_{\mathrm{oc}}$ is the open-circuit voltage; $I_{\mathrm{L}}$ is the current; $R_{\mathrm{i}}$ is the internal resistance; $R_{\mathrm{p}}$ is the polarization resistance; $C_{\mathrm{p}}$ is the polarization capacitance. These parameters can be identified by charge and discharge experiment.

The Ampere-Hour integral method is used to calculate the state of charge (SOC), whose formulation is

$S O C=S O C_{0}-\frac{Q_{\text {use }}}{Q_{\text {cap }}}$

where $S O C_{0}$ is the initial SOC; $Q_{\text {cap }}$ is the nominal battery capacity; $Q_{\text {use }}$ is the consumption, which is calculated by the following equation.

$Q_{\mathrm{use}}=\left\{\begin{array}{c}\frac{1}{\eta_{\text {dis }}} \int I \mathrm{~d} t, I>0 \text { discharge } \\ \eta_{\text {chg }} \int I \mathrm{~d} t, I \leq 0 \text { charge }\end{array}\right.$

where $I$ is the current; $\eta_{\text {chg }}$ and $\eta_{\text {dis }}$ are the efficiencies of charging and discharging, respectively.

\subsection{Modeling of the M/Gs}

The M/G model can be divided into motor model and generator model. For the motor model, the experimental model is adopted, and the complex physical process is ignored. Through the identification experiment, the universal and external characteristics of the motor can be acquired. The generator model is composed of two parts, a mechanical subsystem and electric

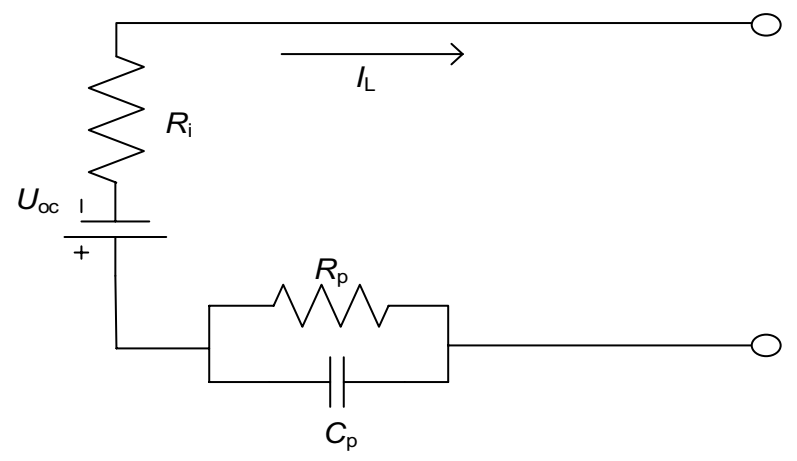

Fig. 2 Equivalent circuit model of the battery subsystem. The mechanical part of the generator is similar to the engine model. It is assumed that the generator will reach the desired torque with a small delay, which is described by a first-order lag function. The electric part is regarded as a controlled current source, which is connected to battery packs and other electric equipment. The electric power supplied to the $\mathrm{M} / \mathrm{G}$ is as follows:

$P_{\mathrm{MG}}=T_{\mathrm{MG}} \omega_{\mathrm{MG}} \eta^{j}$

where $T_{\mathrm{MG}}$ and $\omega_{\mathrm{MG}}$ are the torque and speed of the $\mathrm{M} / \mathrm{G}$, respectively. $\eta$ is the $\mathrm{M} / \mathrm{G}$ efficiency; $j$ denotes the working status. When the $\mathrm{M} / \mathrm{G}$ works as a generator, $j=1$ and the power flows from the $\mathrm{M} / \mathrm{G}$ to the direct current (DC) bus; when the $\mathrm{M} / \mathrm{G}$ works as a motor, $j=-1$ and the power flows from the DC bus to the motor.

\subsection{Modeling of the Transmission System}

Dual-mode transmission system consists of three PGSs, helping to achieve variable speed. The basic relations of the rotational speed and torque are shown as follows:

$n_{\mathrm{s}}+k n_{\mathrm{r}}-(1+k) n_{\mathrm{c}}=0$

$T_{\mathrm{s}}: T_{\mathrm{r}}: T_{\mathrm{c}}=1: k:-(1+k)$

where $n$ and $T$ are rotational speed and torque, respectively. The subscripts s, r, and c donate sun gear, planetary gear, and planet carrier, respectively. $k$ is the structural parameter of the PGS.

In consideration of the structure of the dual-mode EMT, the speed and torque equations of EVT1 and EVT2 are as follows.

EVT1:

$\left[\begin{array}{l}n_{\mathrm{a}} \\ n_{\mathrm{b}}\end{array}\right]=\left[\begin{array}{cc}\frac{\left(1+k_{1}\right)\left(1+k_{2}\right)}{k_{1} k_{2}} & -\frac{\left(1+k_{1}+k_{2}\right)\left(1+k_{3}\right)}{k_{1} k_{2}} \\ 0 & 1+k_{3}\end{array}\right]\left[\begin{array}{l}n_{\mathrm{i}} \\ n_{\mathrm{o}}\end{array}\right]$

$\left[\begin{array}{c}T_{\mathrm{a}} \\ T_{\mathrm{b}}\end{array}\right]=\left[\begin{array}{cc}-\frac{k_{1} k_{2}}{\left(1+k_{1}\right)\left(1+k_{2}\right)} & 0 \\ -\frac{1+k_{1}+k_{2}}{\left(1+k_{1}\right)\left(1+k_{2}\right)} & \frac{1}{1+k_{3}}\end{array}\right]\left[\begin{array}{c}T_{\mathrm{i}} \\ T_{\mathrm{o}}\end{array}\right]$

EVT2:

$\left[\begin{array}{c}n_{\mathrm{a}} \\ n_{\mathrm{b}}\end{array}\right]=\left[\begin{array}{cc}-\frac{1+k_{2}}{k_{1}} & \frac{1+k_{1}+k_{2}}{k_{1}} \\ 1+k_{2} & -k_{2}\end{array}\right]\left[\begin{array}{l}n_{\mathrm{i}} \\ n_{\mathrm{o}}\end{array}\right]$

$\left[\begin{array}{c}T_{\mathrm{a}} \\ T_{\mathrm{b}}\end{array}\right]=\left[\begin{array}{cc}-\frac{k_{1} k_{2}}{\left(1+k_{1}\right)\left(1+k_{2}\right)} & \frac{k_{1}}{1+k_{1}} \\ -\frac{1+k_{1}+k_{2}}{\left(1+k_{1}\right)\left(1+k_{2}\right)} & \frac{1}{1+k_{1}}\end{array}\right]\left[\begin{array}{c}T_{\mathrm{i}} \\ T_{\mathrm{o}}\end{array}\right]$

where $k_{1}, k_{2}, k_{3}$ are structural parameters of PSG-K1, PSG$\mathrm{K} 2$, and PSG-K3. The subscripts a, b, i, and o denote motor A, motor B, the input, and the output, respectively. 
Because the dynamic models in EVT1 and EVT2 can be established by the same method, only the dynamic model in EVT1 is introduced as follows.

$$
\begin{aligned}
\left(J_{\mathrm{e}} \cdot i_{\mathrm{f}}^{2}+J_{\mathrm{f}}+J_{\mathrm{c} 2}\right) \cdot \dot{n}_{\mathrm{e}} / i_{\mathrm{f}} & =i_{\mathrm{f}} \cdot T_{\mathrm{e}}-T_{\mathrm{c} 2} \\
\left(J_{\mathrm{a}}+J_{\mathrm{r} 1}\right) \dot{n}_{\mathrm{a}} & =T_{\mathrm{a}}-T_{\mathrm{r} 1} \\
\left(J_{\mathrm{b}}+J_{\mathrm{s} 1}+J_{\mathrm{s} 2}+J_{\mathrm{s} 3}\right) \dot{n}_{\mathrm{b}} & =T_{\mathrm{b}}-T_{\mathrm{s} 1}-T_{\mathrm{s} 2}-T_{\mathrm{s} 3} \\
\left(J_{\mathrm{c} 1}+J_{\mathrm{r} 2}\right) \dot{n}_{\mathrm{c} 1} & =-T_{\mathrm{r} 2}-T_{\mathrm{c} 1} \\
\left(J_{\mathrm{d}}+J_{\mathrm{c} 3}\right) \dot{n}_{\mathrm{c} 3} & =T_{\mathrm{f}}-T_{\mathrm{c} 3} \\
T_{\mathrm{c} 3}+T_{\mathrm{d}} / i_{\mathrm{d}} & =0
\end{aligned}
$$

where $J$ is the equivalent rotational inertia; $i$ is the gear ratio. The subscripts e, f, and d denote the ICE, the front transmission, and the final transmission. And the subscripts $\mathrm{s} m$, $\mathrm{r} m, \mathrm{c} m(m=1,2,3)$ denote the sun gear, planetary gear, and planet carrier of PGS-Km, respectively. The rotational speed of different parts is as follows.

$$
\begin{aligned}
n_{\mathrm{e}} / i_{\mathrm{f}} & =n_{\mathrm{c} 2} \\
n_{\mathrm{a}} & =n_{\mathrm{r} 1} \\
n_{\mathrm{b}} & =n_{\mathrm{s} 1}=n_{\mathrm{s} 2}=n_{\mathrm{s} 3} \\
n_{\mathrm{c} 1} & =n_{\mathrm{r} 2} \\
n_{\mathrm{r} 3} & =0 \\
n_{\mathrm{c} 3} & =i_{\mathrm{d}} V / R_{\mathrm{w}}
\end{aligned}
$$

where $R_{\mathrm{w}}$ is the tire rolling radius; $V$ is the vehicle speed.

\section{Design of the Double Closed-Loop Control Strategy}

\subsection{Double Closed-Loop Control Strategy}

In the proposed control strategy, a rule-based power distribution control strategy is used to determine the steady-state target power of each power source. To achieve the battery steady-state target power, the motor dynamic compensation torque needs to be provided. Thus, the battery power closed-loop feedback control strategy is applied. However, due to the interference from other electronic equipment and the complex coupling mechanism of the EMT system, the electric power cannot achieve the target value timely and keep stable. Therefore, a motor coordinated control strategy is proposed, which is also a closed-loop control strategy. The above control strategies constitute the double closed-loop coordinated control strategy. Figure 3 shows the structure of the proposed control strategy which will be further explained in the following sections.

\subsection{Power Distribution Strategy}

To achieve reasonable power distribution, the electric power demand needs to be accurately estimated. According to system settings, it can be estimated based on the voltage and current of the DC bus. The DC bus voltage equals the battery voltage because battery packs are directly connected to the M/G. With the battery model used in this study, the electric power demand can be estimated as follows:

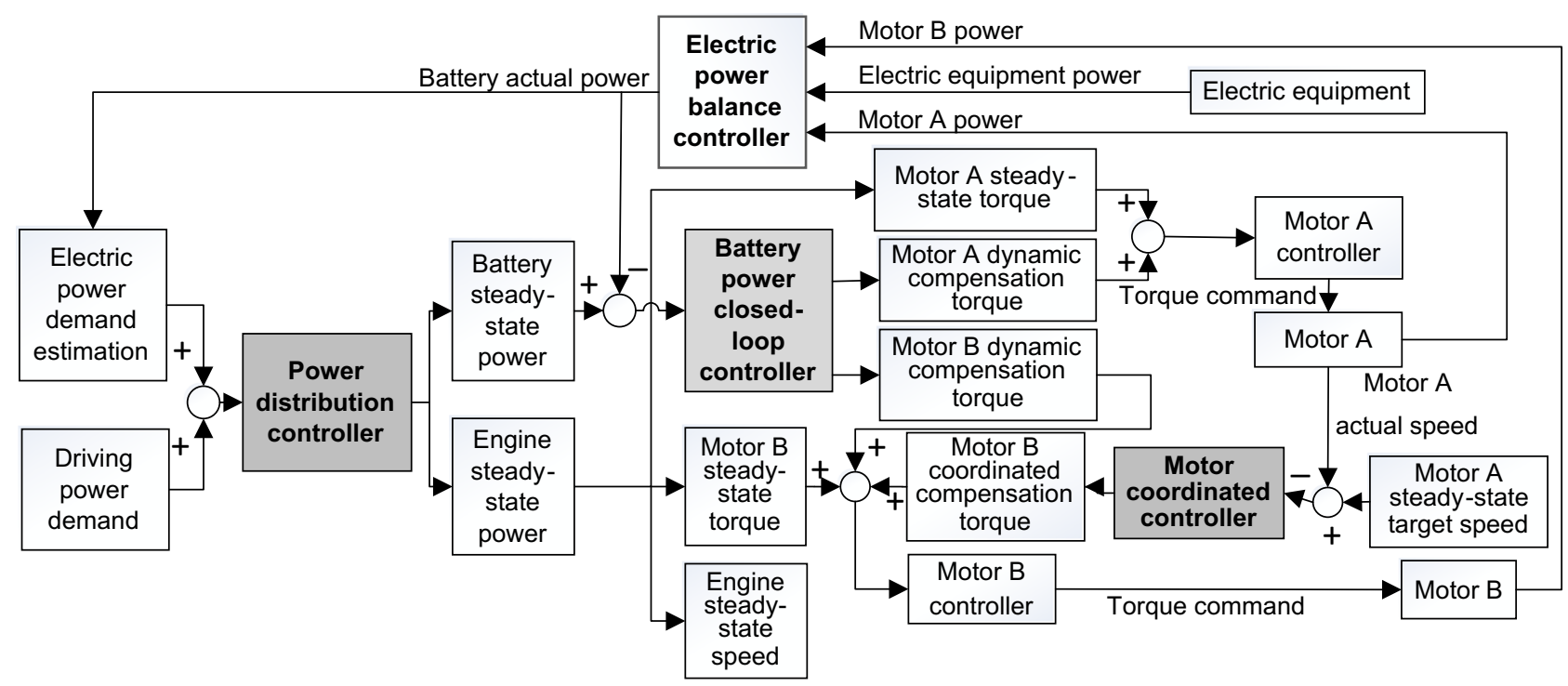

Fig. 3 Double closed-loop multi-power coordinated control strategy 
$P_{\text {ele_dem }}(z)=\rho U(z) I(z)$

where $P_{\text {ele_dem }}$ is the electric power demand; $U(z)$ and $I(z)$ are the voltage and current of the DC bus at moment $z$, and $\rho$ is a constant. If there is a demand for electric power, $\rho=1$; otherwise, $\rho=-1$. Meanwhile, according to the driving condition, the driving power demand can be determined. The driving power demand and electric power demand constitute the overall power demand.

On the basis of the predetermined distribution rules, the steady-state target power of the battery and the ICE can be determined. The steady-state target power of the battery can be determined based on its SOC and the driving condition. The steady-state target power of the ICE can be obtained by calculating the difference between the overall power demand and battery steady-state power. It is noted that the battery supplies power only under special conditions, such as full throttle. In other conditions, the engine will supply all power to satisfy the overall power demand. After power distribution, the steady-state target values of components need to be determined. The speed control is applied to the ICE, whereas the torque control is applied to the M/G. Therefore, if the engine power is determined, the engine target speed can be obtained through the engine universal characteristic curve based on the engine high-efficiency area. The steady-state motor target torque can be calculated using a similar method. The proposed power distribution control strategy is shown in Fig. 4.

\subsection{Battery Power Closed-Loop Feedback Control Strategy}

To illustrate the basic idea of the battery power closed-loop feedback control strategy, the electric power balance equation is given:

$P_{\mathrm{bat}}+P_{a} \eta_{\mathrm{a}}^{-\operatorname{sgn}\left(P_{\mathrm{a}}\right)}+P_{\mathrm{b}} \eta_{\mathrm{b}}^{-\operatorname{sgn}\left(P_{\mathrm{b}}\right)}+\sum P_{\text {eqi }}=0$

where $P_{\text {bat }}$ is the battery power; $P_{\text {eqi }}$ is the electric equipment power; $P_{\mathrm{a}}$ and $P_{\mathrm{b}}$ are the power of M/G A and M/G B, respectively; $\eta$ is the motor efficiency, whose value depends on the working status of the $\mathrm{M} / \mathrm{G}$.

Because the electric power always keeps balance during the working process, the battery power can only be decided by the M/Gs power. As mentioned in Sect. 3.2, the torque control is applied to the M/G. Thus, the M/Gs power can be affected by providing the dynamic compensation torque.

Figure 5 shows the structure of the battery closed-loop feedback control strategy. In this strategy, the control objective is the battery actual power, which can be obtained according to the working voltage and current. The control variables are the dynamic compensation torque of $\mathrm{M} / \mathrm{Gs}$, which are decided by the deviation between the actual and target battery power.

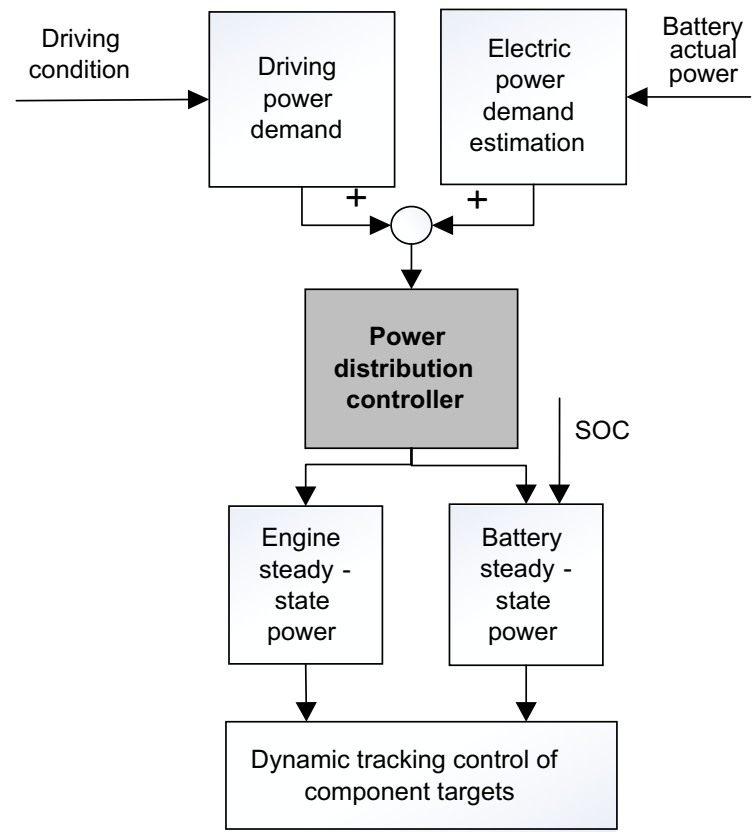

Fig. 4 Power distribution control strategy

The relationship between the dynamic compensation torque and the deviation is determined by the fuzzy PID algorithm. The PID parameters are adjusted in real time so that they can adapt to multiple driving conditions. At this time, the actual torque of $\mathrm{M} / \mathrm{Gs}$ consists of two parts: the steady-state torque decided by the power distribution strategy and the dynamic compensation torque calculated by the battery power closedloop control strategy. Therefore, the power of M/Gs can be adjusted according to the battery state, and the battery power will follow the steady-state target power.

\subsection{Model-Based Motor Coordinated Control Strategy}

To adjust the battery power to the target value and satisfy the power demand of other electric equipment, the motor power and working state need to be controlled coordinately. In addition, the motor speed needs to be stable under interference. According to Sect. 2.4, the dynamic model of the dual-mode EMT system is given as follows:

EVT1:

$\frac{k_{1} k_{2}}{\left(1+k_{1}\right)\left(1+k_{2}\right)} T_{\mathrm{i}}+T_{\mathrm{a}}=J_{\mathrm{a}} \frac{\mathrm{d} n_{\mathrm{a}}}{\mathrm{d} t}$

$\frac{1+k_{1}+k_{2}}{\left(1+k_{1}\right)\left(1+k_{2}\right)} T_{\mathrm{i}}-\frac{1}{1+k_{3}} T_{\mathrm{o}}+T_{\mathrm{b}}=J_{\mathrm{b}} \frac{\mathrm{d} n_{\mathrm{b}}}{\mathrm{d} t}$ 


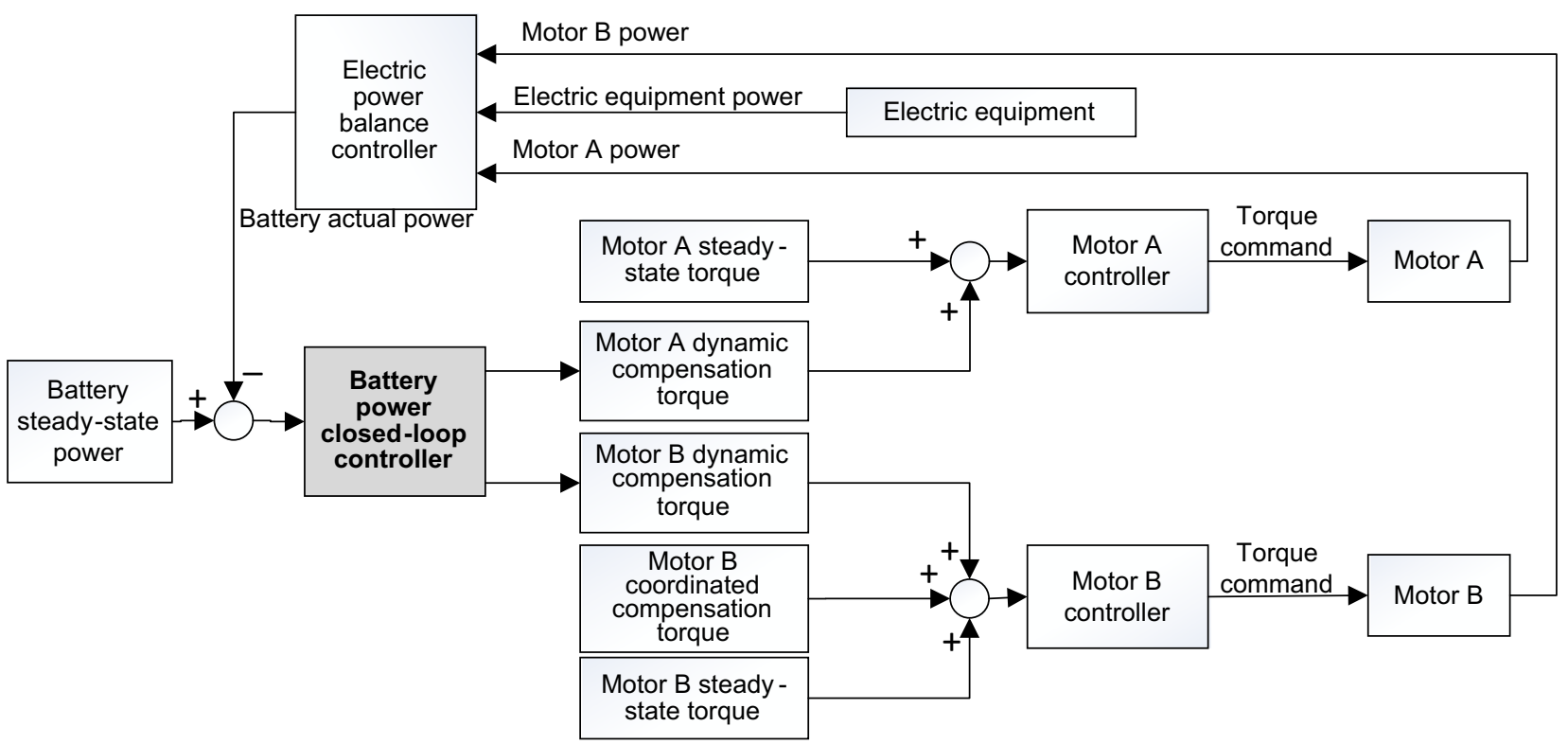

Fig. 5 Battery closed-loop feedback control strategy

EVT2:

$$
\begin{aligned}
& \frac{k_{1} k_{2}}{\left(1+k_{1}\right)\left(1+k_{2}\right)} T_{\mathrm{i}}-\frac{k_{1}}{1+k_{1}} T_{\mathrm{o}}+T_{\mathrm{a}}=J_{\mathrm{a}} \frac{\mathrm{d} n_{\mathrm{a}}}{\mathrm{d} t} \\
& \frac{1+k_{1}+k_{2}}{\left(1+k_{1}\right)\left(1+k_{2}\right)} T_{\mathrm{i}}-\frac{1}{1+k_{1}} T_{\mathrm{o}}+T_{\mathrm{b}}=J_{\mathrm{b}} \frac{\mathrm{d} n_{\mathrm{b}}}{\mathrm{d} t}
\end{aligned}
$$

The above equations show that small deviations in the distribution result will lead to fluctuations in the motor speed. This will also affect the stability of the electric power. For instance, if the engine torque cannot follow the change in the motor torque, the speed of motors will decrease. Then, the output speed and torque of the EMT system will decrease. As a result, the system fails to supply electric power stably.

To ensure a rapid and stable electric power supply, the model-based motor coordinated control strategy is proposed. This control strategy can coordinate the control of the motor and generator, change their working status, and quickly meet the electric power demand.

When the system supplies the electric power, it is desirable to keep the dynamic state of the vehicle as unchanged as possible. In other words, the output parameters, such as the output power $P_{\mathrm{o}}$, output speed $n_{\mathrm{o}}$, and output torque $T_{\mathrm{o}}$, cannot be varied, that is, $\Delta P_{\mathrm{o}}=0$. According to Eqs. (15)-(18), the relationship between the power changes of each component can be expressed as follows:

\section{EVT1:}

$$
\begin{aligned}
\Delta P_{\mathrm{a}} & =-\Delta P_{\mathrm{i}}+\frac{\left(1+k_{1}+k_{2}\right)\left(1+k_{3}\right)}{\left(1+k_{1}\right)\left(1+k_{2}\right)} n_{\mathrm{o}} \Delta T_{\mathrm{i}} \\
& =-\Delta P_{\mathrm{i}}-\frac{\left(1+k_{1}+k_{2}\right)\left(1+k_{3}\right)}{k_{1} k_{2}} n_{\mathrm{o}} \Delta T_{\mathrm{a}}
\end{aligned}
$$

$$
\begin{aligned}
\Delta P_{\mathrm{b}} & =-\frac{\left(1+k_{1}+k_{2}\right)\left(1+k_{3}\right)}{\left(1+k_{1}\right)\left(1+k_{2}\right)} n_{\mathrm{o}} \Delta T_{\mathrm{i}} \\
& =\left(1+k_{3}\right) n_{\mathrm{o}} \Delta T_{\mathrm{b}} \\
& =\frac{\left(1+k_{1}+k_{2}\right)\left(1+k_{3}\right)}{k_{1} k_{2}} n_{\mathrm{o}} \Delta T_{\mathrm{a}}
\end{aligned}
$$

EVT2:

$$
\begin{aligned}
\Delta P_{\mathrm{a}} & =\frac{k_{2}}{1+k_{1}} \Delta P_{\mathrm{i}}-\frac{1+k_{2}}{1+k_{1}} T_{\mathrm{o}} \Delta n_{\mathrm{i}}-\frac{\left(1+k_{1}+k_{2}\right) k_{2}}{\left(1+k_{1}\right)\left(1+k_{2}\right)} n_{\mathrm{o}} \Delta T_{\mathrm{i}} \\
& =\frac{k_{2}}{1+k_{1}} \Delta P_{\mathrm{i}}+\frac{k_{1}}{1+k_{1}} T_{\mathrm{o}} \Delta n_{\mathrm{a}}+\frac{1+k_{1}+k_{2}}{k_{1}} n_{\mathrm{o}} \Delta T_{\mathrm{a}} \\
\Delta P_{\mathrm{b}} & =-\frac{1+k_{1}+k_{2}}{1+k_{1}} \Delta P_{\mathrm{i}}+\frac{1+k_{2}}{1+k_{1}} T_{\mathrm{o}} \Delta n_{\mathrm{i}}+\frac{\left(1+k_{1}+k_{2}\right) k_{2}}{\left(1+k_{1}\right)\left(1+k_{2}\right)} n_{\mathrm{o}} \Delta T_{\mathrm{i}} \\
& =-\frac{1+k_{1}+k_{2}}{1+k_{1}} \Delta P_{\mathrm{i}}+\frac{1}{1+k_{1}} T_{\mathrm{o}} \Delta n_{\mathrm{b}}-k_{2} n_{\mathrm{o}} \Delta T_{\mathrm{b}} \\
& =-\frac{1+k_{1}+k_{2}}{1+k_{1}} \Delta P_{\mathrm{i}}-\frac{k_{1}}{1+k_{1}} T_{\mathrm{o}} \Delta n_{\mathrm{a}}-\frac{1+k_{1}+k_{2}}{k_{1}} n_{\mathrm{o}} \Delta T_{\mathrm{a}}
\end{aligned}
$$




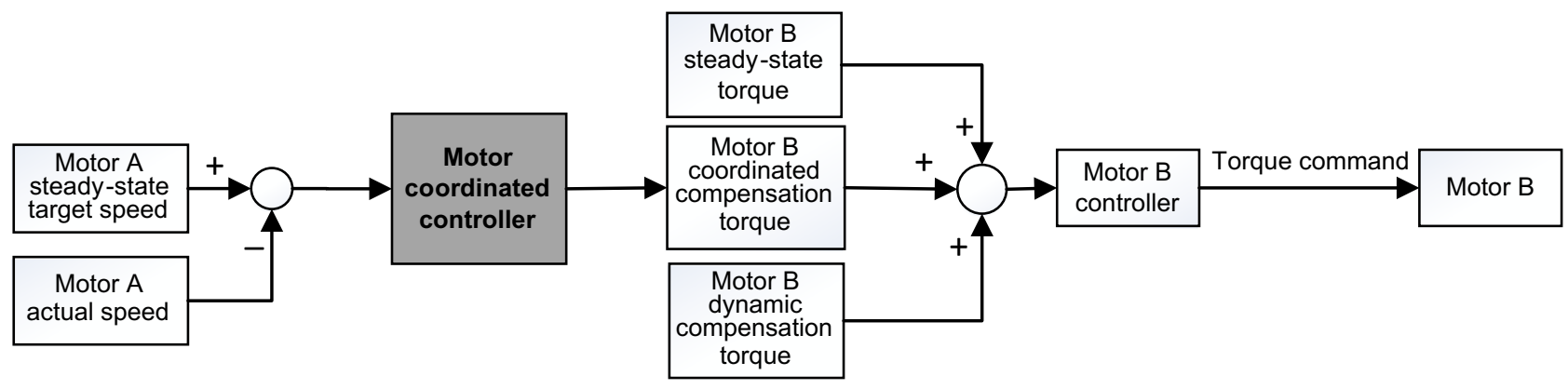

Fig. 6 Electric power coordinated control strategy

where $\Delta P, \Delta T$, and $\Delta n$ are the variations in the power, torque, and speed, respectively. The meanings of subscripts are consistent with that in Sect. 2.4.

When the system works and the battery power remains constant, the engine will provide additional power for the electrical equipment. Under the two work modes, the following equation is satisfied.

$\Delta P_{\mathrm{a}}+\Delta P_{\mathrm{b}}=-\Delta P_{\mathrm{i}}$

The additional engine power equals the sum of power changes of the two M/Gs. Therefore, the electric power demand can be rapidly satisfied by coordinating two motors.

Figure 6 shows the working process of the motor coordinated power supply control strategy. Its basic control principle is as follows: According to the current working mode, the steady-state target speed of motor A is determined. Then, the speed deviation of motor $\mathrm{A}$ is taken as the input, and the coordinated compensation torque of motor $\mathrm{B}$ is calculated by the fuzzy PID algorithm. As for motor B, the actual torque consists of three parts: steady-state torque, dynamic compensation torque, and coordinated compensation torque. By compensating and coordinating the torque of motor $\mathrm{B}$, it will reach the required speed. As both motors work at the steady-state target speed, the output speed will maintain its steady-state speed. Thus, the output torque will not decrease.

Under the battery closed-loop feedback control, the change in battery power will follow the predetermined trajectory. Meanwhile, with the help of the coupling relationship among components, the motor coordinated control strategy will enable the system to rapidly supply electric power and keep it stable. In summary, the double closed-loop feedback strategy ensures the precision of the mechanical and electric power distribution, while supplying the electric power rapidly and stably.

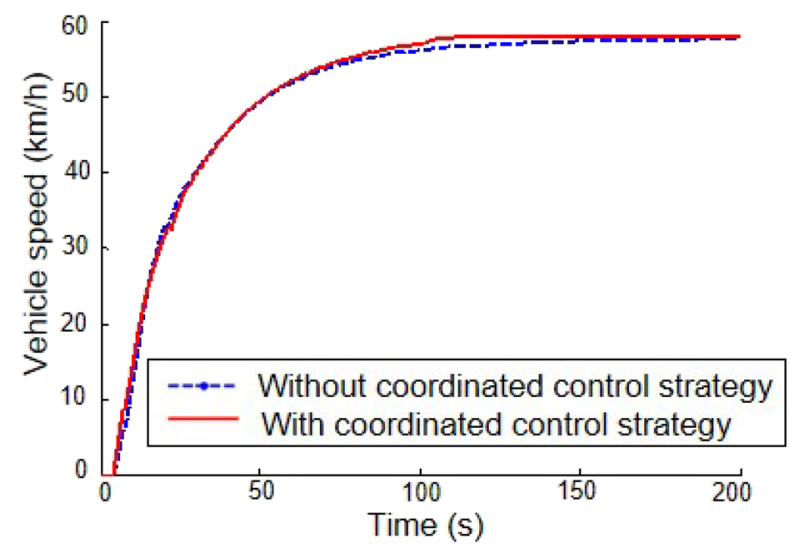

Fig. 7 Vehicle speed when the throttle opening is $60 \%$

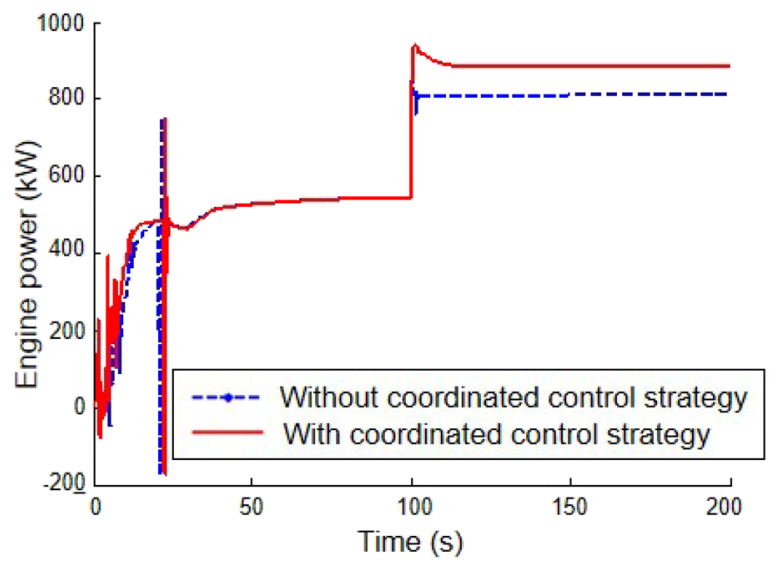

Fig. 8 Engine power when the throttle opening is $60 \%$

\section{Simulation Results}

To verify the feasibility of the proposed control strategy, models mentioned in Sect. 2 are constructed based on the MATLAB/Simulink platform. Then, the simulation is performed under various working conditions. 


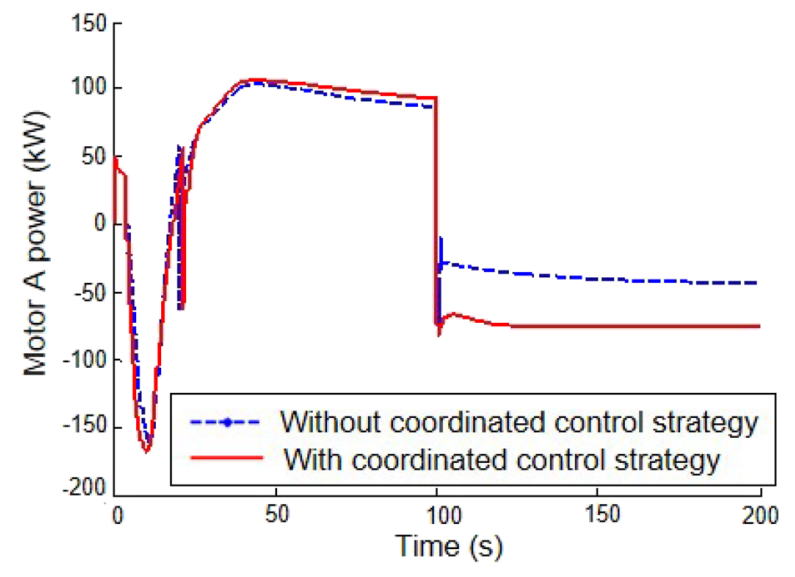

Fig. 9 Motor A power when the throttle opening is $60 \%$

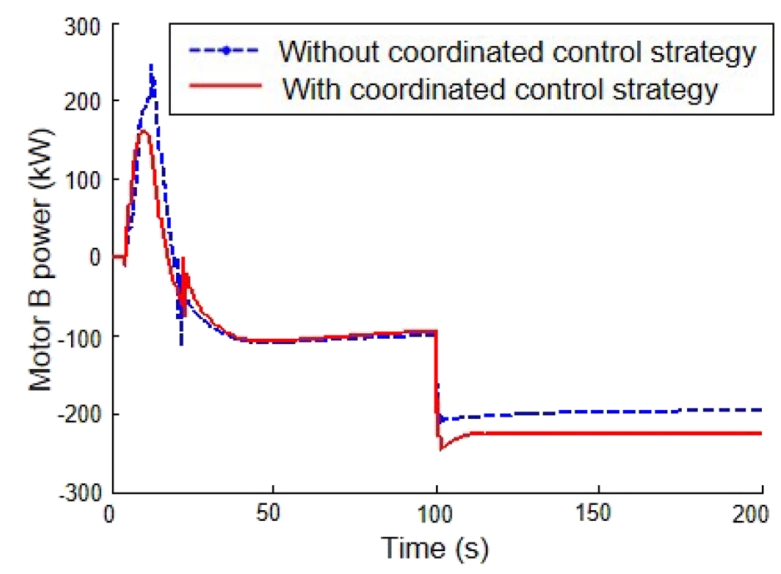

Fig. 10 Motor B power when the throttle opening is $60 \%$

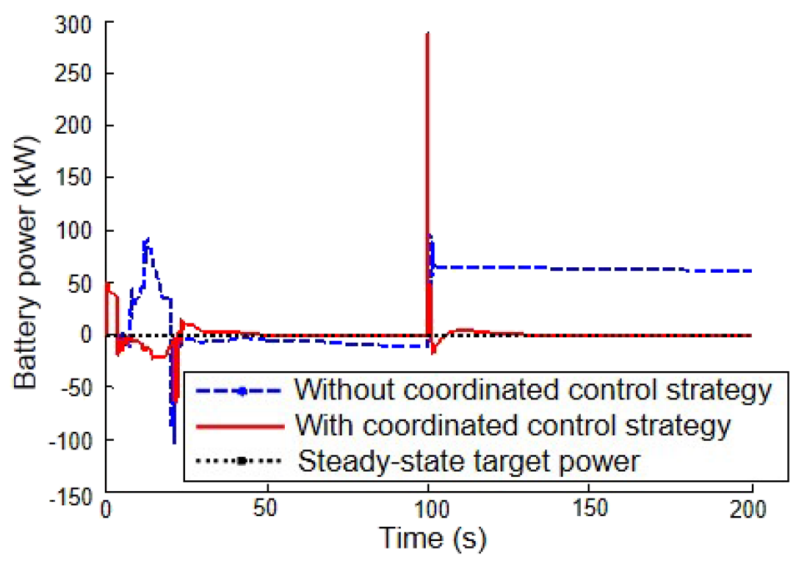

Fig. 11 Battery power when the throttle opening is $60 \%$

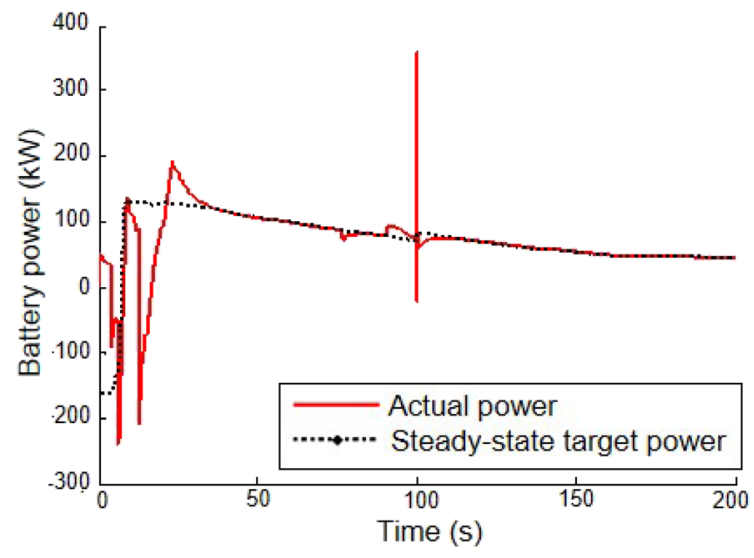

Fig. 12 Battery power when the throttle opening is $100 \%$

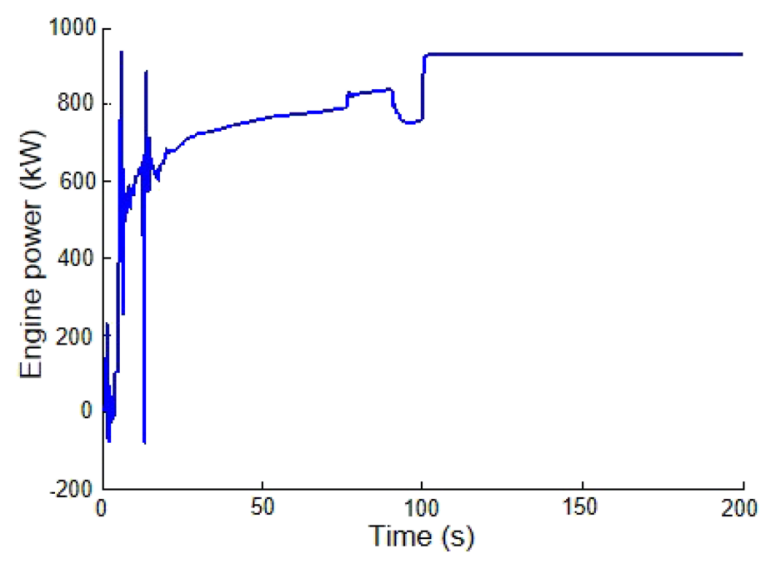

Fig. 13 Engine power when the throttle opening is $100 \%$

The simulation scenario is set under the condition where the system needs to supply $300 \mathrm{~kW}$ electric power at $100 \mathrm{~s}$, and the results at a $60 \%$ throttle opening as illustrated in Figs. 7, 8, 9, 10, and 11. At $100 \mathrm{~s}$, because of the slow response of the engine, the battery covers instantaneous power demand. Then, the engine gradually reaches the required power and provides additional power for the electric device. During this precess, the two motors coordinate with each other and change their work status to provide $300 \mathrm{~kW}$ electric power while the battery power gradually recovers its target power. Without the proposed strategy, the system responds slowly, and the ultimate control state may deviate from the steady-state control target due to the error of the transmission efficiency model. Clearly, the performance of the electric power response has been greatly improved with the proposed control strategy. During the coordination process, the dynamic performance of the vehicle is unaffected, as Fig. 7 shows. Figures 8, 9, and 10 show that when the system is stable, the actual power of the mechanical and electric systems is equal to the steady-state target power value. Figure 11 shows that the battery power is significantly increased 


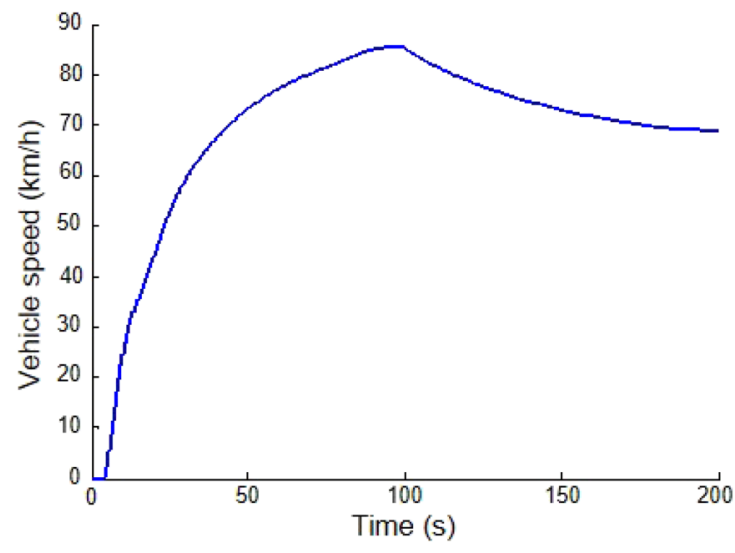

Fig. 14 Vehicle speed when the throttle opening is $100 \%$

Table 1 Basic parameters for the test bench

\begin{tabular}{ll}
\hline Parameters & Value \\
\hline Vehicle mass & $2000 \mathrm{~kg}$ \\
Maximum speed & $170 \mathrm{~km} / \mathrm{h}$ \\
Wheel radius & $0.388 \mathrm{~m}$ \\
Axle ratio & 4.24 \\
Shifting speed & $55 \mathrm{~km} / \mathrm{h}$ \\
Engine power & $140 \mathrm{~kW}$ \\
Motor power & $60 \mathrm{~kW}$ \\
Battery power & $150 \mathrm{~kW}$ \\
\hline
\end{tabular}

with adjustment speed. The distribution precision and supply speed are improved through the interaction among the engine and motors using the proposed control strategy.

When the throttle opening is at $100 \%$, the electric devices still demand $300 \mathrm{~kW}$ electric power at 100 s. In Fig. 12, the battery packs instantaneously provide $300 \mathrm{~kW}$ electric power. Then, the engine achieves its peak power as shown in Fig. 13. Under the coordinated control of the motors, the battery power can follow its predetermined target power. However, as the engine reaches the peak power, the total power demand will exceed the range that the system can provide. Therefore, to meet the demand of the electric power supply, the system can only sacrifice its dynamic performance, which will result in a decrease in speed. Finally, the vehicle eventually travels at $68 \mathrm{~km} / \mathrm{h}$, as shown in Fig. 14 .

\section{Test Results}

To verify the effectiveness of the electric power coordinated control strategy, the low-power EMT test bench is built. The test bench simulates a heavy HEV, and its basic parameters are shown in Table 1. The performances and structure of the test bench and that of a heavy HEV are similar. The only difference between the test bench and heavy HEV with a dualmode EMT system is the rated power. Due to the reduction in the rated power, the arrangement and installation of the test bench become more convenient, and the reliability and safety of the experiment are improved. Therefore, this test bench is feasible in verifying the proposed control strategy.

The test bench, which includes a diesel engine, front transmission, power coupling mechanism, battery packs, motors and controllers, dynamometer, and control console, is shown in Fig. 15. A rapid electronic control unit is used to calculate the working state of each component using the acquired data. The engine controller and motor controller receive the commands from the control console and act along the given target values.

To verify the feasibility of the proposed control strategy, two experimental scenarios are designed. In scenario 1, the purpose is to verify the effectiveness of the power distribution control strategy. First, the system works stably under the rule-based power distribution control. Then, at $60 \mathrm{~s}$, the proposed control strategy is applied. The changes in the actual power, vehicle speed, and power distribution can be observed in Figs. 16, 17, 18, 19, and 20.

The target power of the battery given by the rule-based power distribution control strategy is 0 . However, Fig. 20

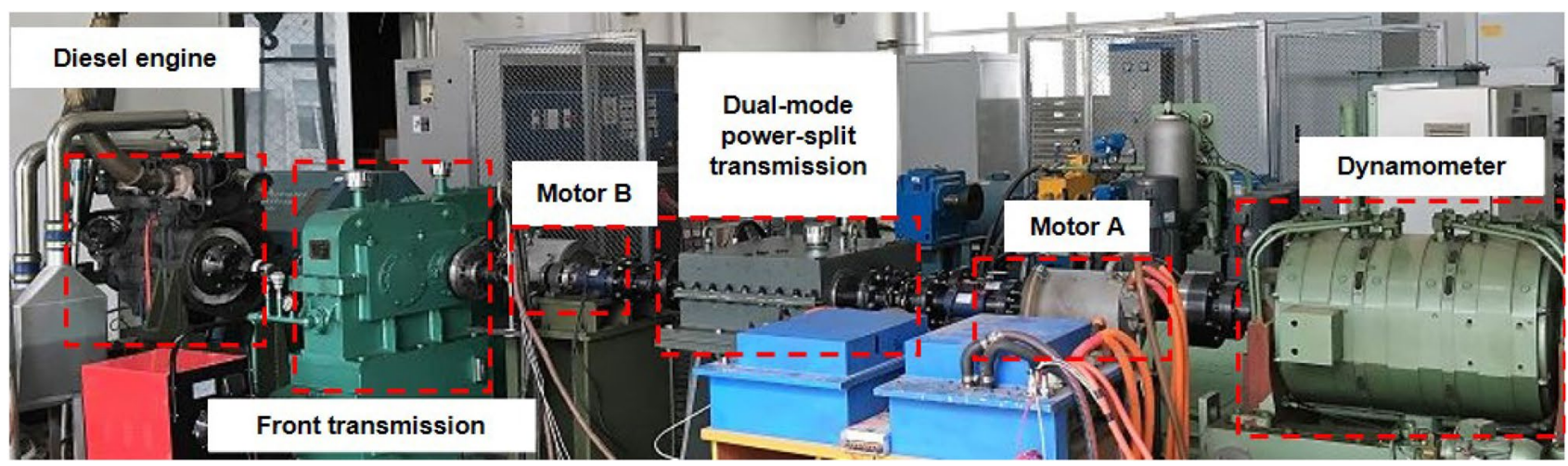

Fig. 15 Low-power EMT test bench 

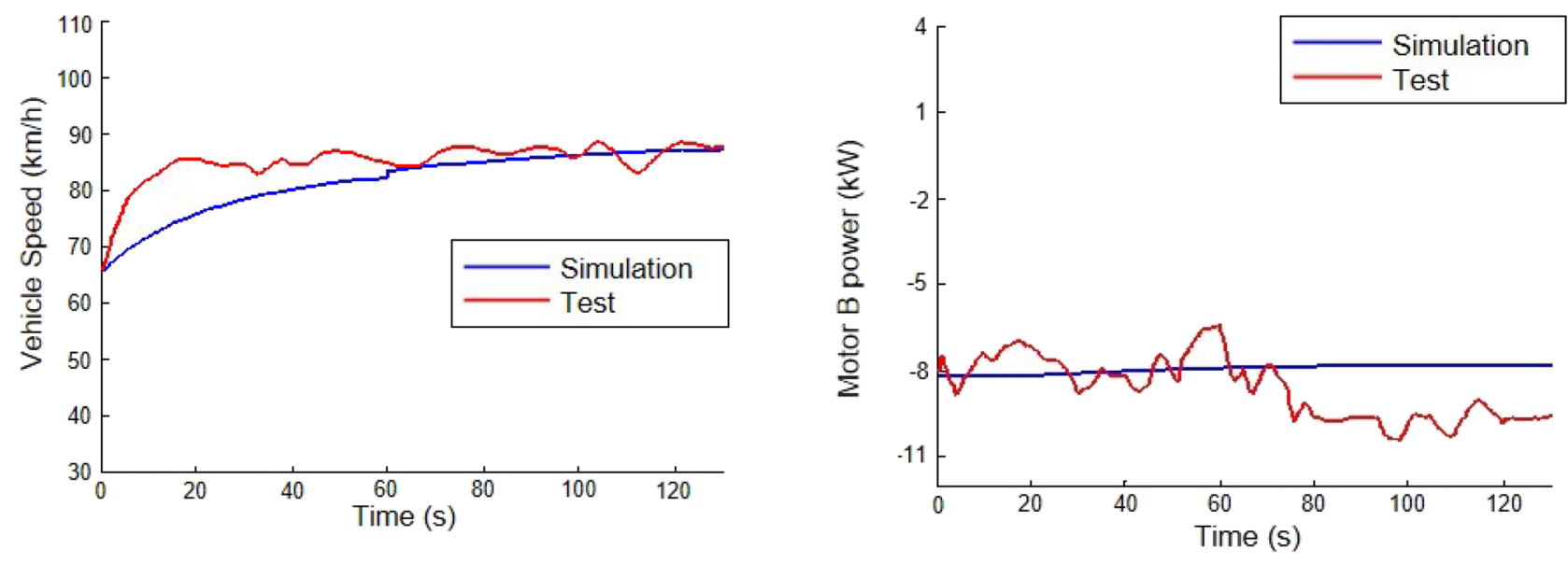

Fig. 16 Vehicle speed in scenario 1

Fig. 19 Motor B power in scenario 1

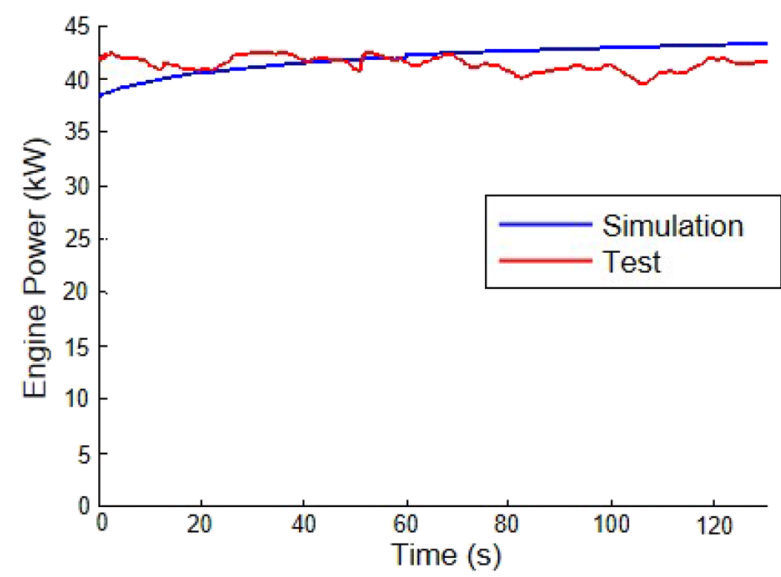

Fig. 17 Comparison of the engine power in scenario 1

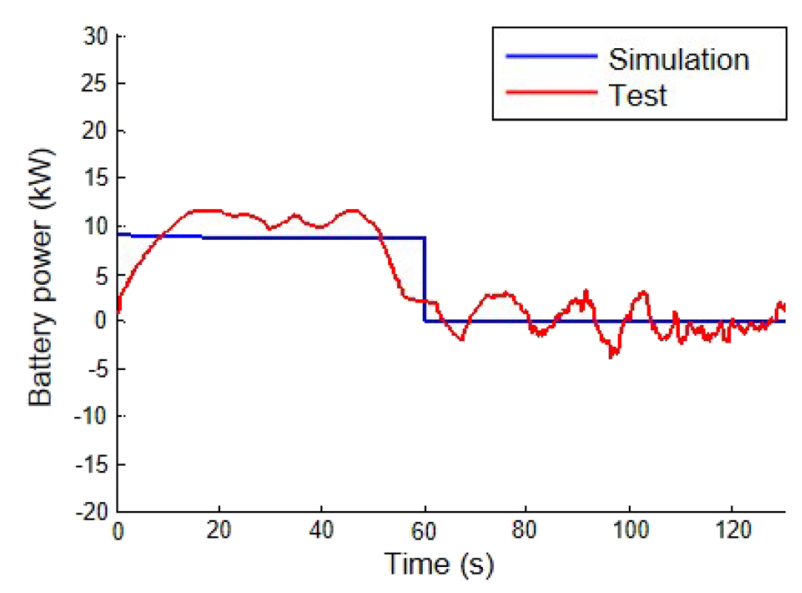

Fig. 20 Battery power in scenario 1

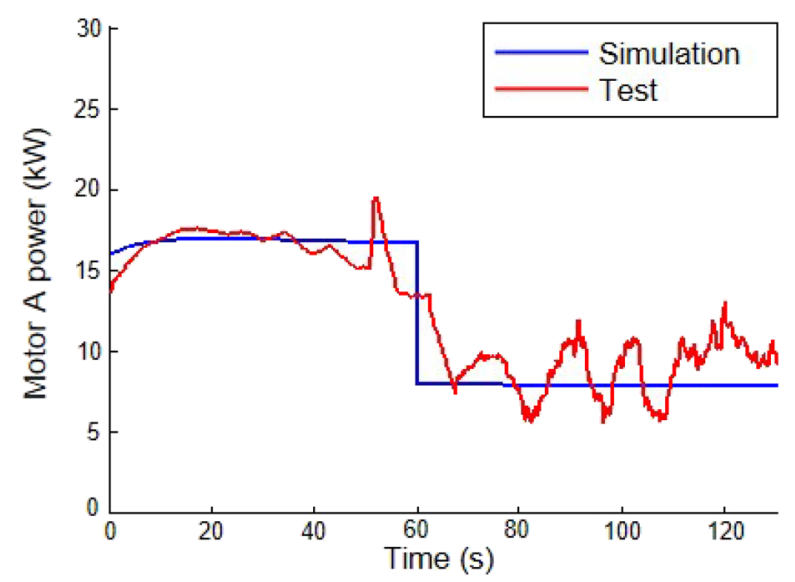

Fig. 18 Motor A power in scenario 1

shows that battery packs have been discharged at $10 \mathrm{~kW}$ before the proposed strategy is applied. Clearly, the battery power always deviates from the desired trajectory. After the proposed control strategy is applied, the two motors cooperate and change their working condition so that the battery power can follow its target value. Meanwhile, the vehicle maintains the original speed.

In scenario 2, the effect of the proposed control strategy on the response speed and stability of the power supply is studied. The test process is similar to that of scenario 1 . The difference is that the proposed control strategy is applied at $50 \mathrm{~s}$, and the system requires $20 \mathrm{~kW}$ of power for battery charging. In this way, the situation where the electrical device requires the EMT system to supply electric power is simulated. The results of scenario 2 are shown in Figs. 21, 22, 23, 24, and 25.

In the first $50 \mathrm{~s}$, the test bench runs stably under the rulebased power distribution control strategy. At $50 \mathrm{~s}$, the system has to supply $20 \mathrm{~kW}$ electric power to charge the battery. 


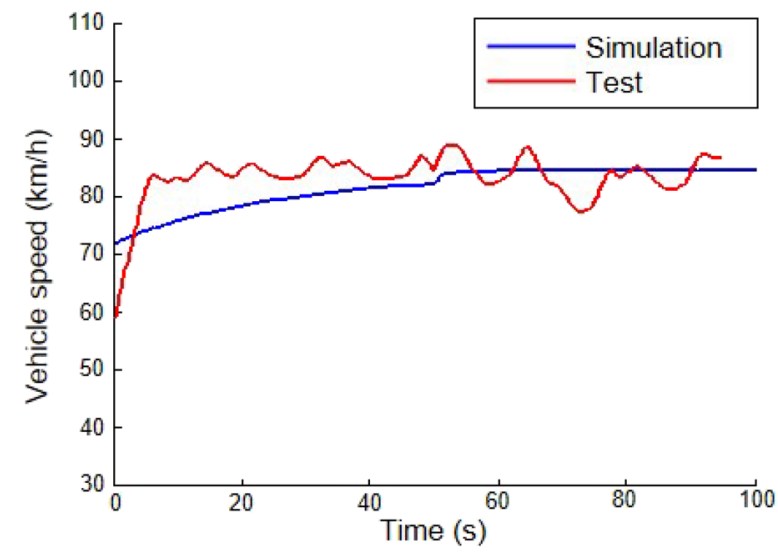

Fig. 21 Vehicle speed in scenario 2

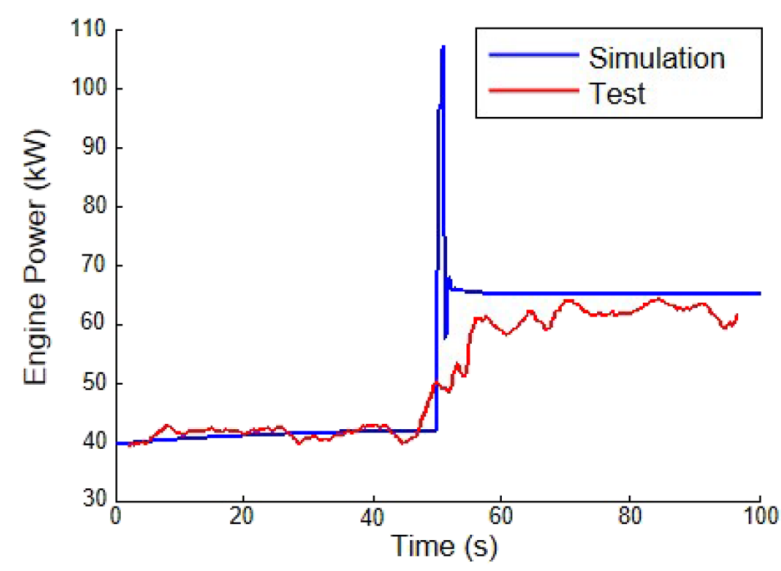

Fig. 22 Engine power in scenario 2

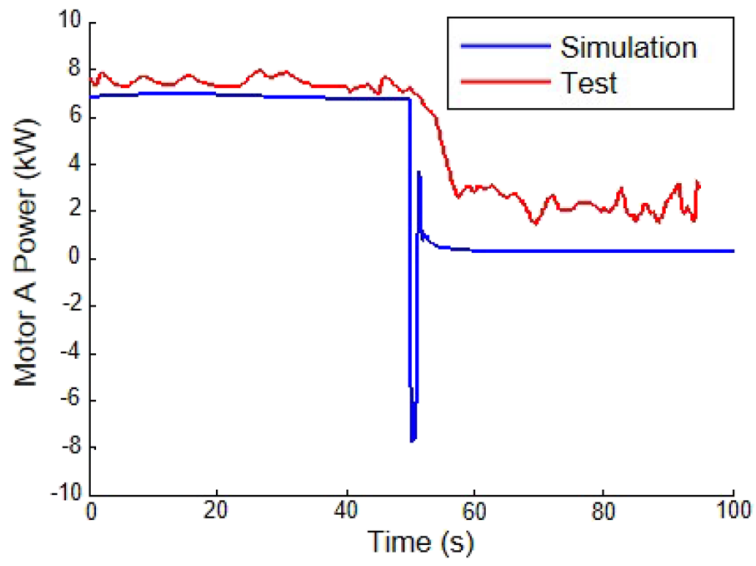

Fig. 23 Motor A power in scenario 2

At this point, the proposed control strategy is applied. The engine outputs additional $20 \mathrm{~kW}$ power for the battery charging. The two M/Gs also adjust their working state to ensure

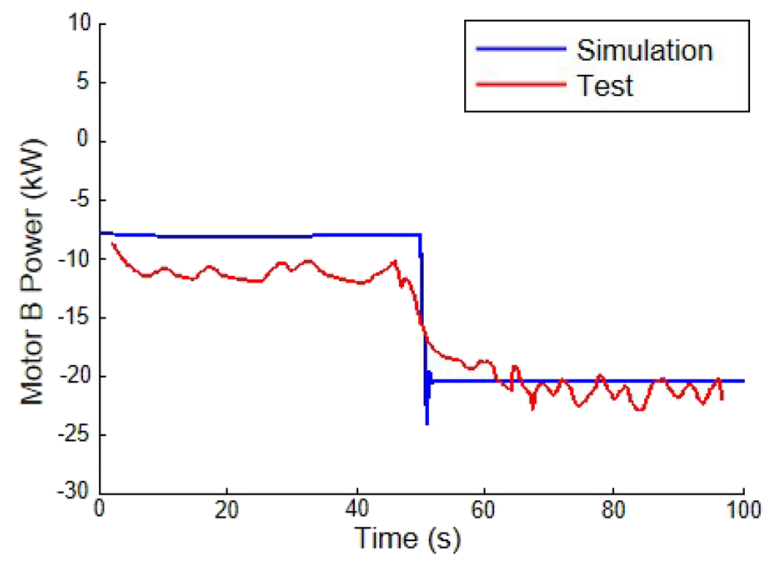

Fig. 24 Motor B power in scenario 2

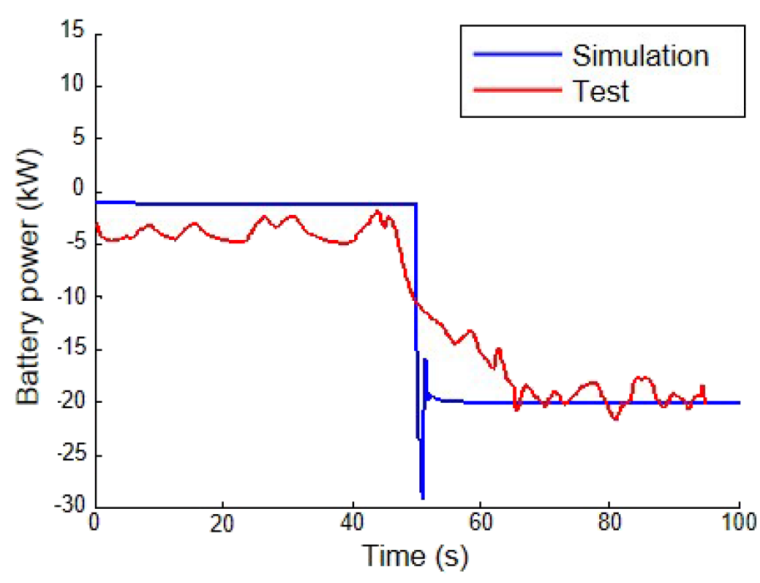

Fig. 25 Battery power in scenario 2

the response speed and stability of the electric power supply. To conclude, the proposed control strategy can realize fast response and the charging stability.

\section{Conclusions}

This paper presents a model-based double closed-loop coordinated control strategy for the EMT of the heavy powersplit HEVs. The control strategy consists of three parts: the power distribution strategy, the battery closed-loop feedback control strategy, and the model-based motor coordinated control strategy. The simulation and test results demonstrate the validity of the approach. The following conclusions are drawn:

1. Under the proposed power distribution strategy, the electric power demand can be accurately estimated, and the 
battery and the engine power are precisely distributed to satisfy the overall power demand.

2. The proposed battery closed-loop feedback control strategy can effectively eliminate the deviation between the actual battery power and the target battery power.

3. The proposed motor coordinated control strategy addressed the problems caused by the interference from other electronic equipment and the complex coupling mechanism of the EMT system. With this control strategy, the EMT system can make rapid response and maintain good stability.

In conclusion, the proposed model-based double closed-loop coordinated control strategy can greatly improve the performance of heavy power-split HEVs regarding the system stability, response speed, and accuracy. Besides, it shows good real-time performance. These are of great significance for expanding the application field of the heavy power-split HEVs.

Future work will focus on the improvement of the proposed control strategy algorithm, especially the robustness of the algorithm will be improved while ensuring the realtime performance. Moreover, the proposed control strategy will be further optimized under complex operating conditions.

Acknowledgements The authors are grateful for the financial support from the National Natural Science Foundation of China (Grant Nos. 51705480, No. 51575043, Nos.51975048, U1564210, and U1764257).

\section{Compliance with Ethical Standards}

Conflict of interest On behalf of all the authors, the corresponding author states that there is no conflict of interest.

Open Access This article is licensed under a Creative Commons Attribution 4.0 International License, which permits use, sharing, adaptation, distribution and reproduction in any medium or format, as long as you give appropriate credit to the original author(s) and the source, provide a link to the Creative Commons licence, and indicate if changes were made. The images or other third party material in this article are included in the article's Creative Commons licence, unless indicated otherwise in a credit line to the material. If material is not included in the article's Creative Commons licence and your intended use is not permitted by statutory regulation or exceeds the permitted use, you will need to obtain permission directly from the copyright holder. To view a copy of this licence, visit http://creativecommons.org/licenses/by/4.0/.

\section{References}

1. Chan, C., Bouscayrol, A., Chen, K.: Electric, hybrid, and fuel-cell vehicles: architectures and modeling. IEEE Trans. Veh. Technol. 59(2), 589-598 (2010)
2. Li, H., Yan, Q., Xiang, C., et al.: Analysis method and principle of dual-mode electro-mechanical variable transmission program. Chin J. Mech. Eng. 25(3), 524-529 (2012)

3. Mashadi, B., Emadi, S.A.M.: Dual-mode power-split transmission for hybrid electric vehicles. IEEE Trans. Veh. Technol. 59(7), 3223-3232 (2010)

4. Ma, X., Zhang, Y., Yin, C., et al.: Multi-objective optimizaiton considering battery degradation for a multi-mode power-split electric vehicle. Appl. Sci. 10(7), 975 (2017)

5. Yang, C., Jiao, X., Li, L., et al.: A robust $\mathrm{H} \infty$ control-based hierarchical mode transition control system for plug-in hybrid electric vehicle. Mech. Syst. Signal Process. 99, 326-344 (2018)

6. Huang, K., Xiang, C., Ma, Y., et al.: Mode shift control for a hybrid heavy-duty vehicle with power-split transmission. Energies 10(2), 177 (2017)

7. Ying, X., Cong, Z.: Real-time optimization power-split strategy for hybrid electric vehicles. Sci. China Technol. Sci. 59(5), 814824 (2016)

8. Denis, N., Dubois, M.R., Trovao, J.P.F., Desrochers, A.: Power split strategy optimization of a plug-in parallel hybrid electric vehicle. IEEE Trans. Veh. Technol. 67(1), 315-326 (2018)

9. Anselma, P.G., Huo, Y., Roeleveld, J., et al.: Integration of on-line control in optimal design of multimode power-split hybrid electric vehicle powertrains. IEEE Trans. Veh. Technol. 68(4), 3436-3445 (2019)

10. Fan, J., Qin, Z., Luo, Y., et al.: A novel power management strategy for hybrid off-road vehicles. Control Eng. Pract. (2020). https ://doi.org/10.1016/j.conengprac.2020.104452

11. Wang, Y., Sun, Z.: Dynamic analysis and multivariable transient control of the power-split hybrid powertrain. IEEE/ASME Trans. Mech. 20(6), 3085-3097 (2015)

12. Syed, F., Kuang, M., Ying, H.: Active damping wheel-torque control system to reduce driveline oscillations in a power-split hybrid electric vehicle. IEEE Trans. Veh. Technol. 58(9), 4769-4785 (2009)

13. Zhang, X., Liu, H., Zhan, Z., et al.: Modelling and active damping of engine torque ripple in a power-split hybrid electric vehicle. Control Eng. Pract. (2020). https://doi.org/10.1016/j.conengprac .2020 .104634

14. Yang, Y., Wang, C., Zhang, Q., et al.: Torque coordination control during braking mode switch for a plug-in hybrid electric vehicle. Energies 10(11), 1684 (2017)

15. Shuai, Z., Li, C., Gai, J., et al.: Coordinated motion and powertrain control of a series-parallel hybrid $8 \times 8$ vehicle with electric wheels. Mech. Syst. Signal Process. 120, 560-583 (2019)

16. Wang, C., Zhao, Z., Zhang, T., et al.: Mode transition coordinated control for a compound power-split hybrid car. Mech. Syst. Signal Process. 87, 192-205 (2017)

17. Zuo, Y., Sun, R., Zang, J., et al.: Coordinated control for driving mode switching of hybrid electirc vehicles. Shock Vib. (2020). https://doi.org/10.1155/2020/7325456

18. Sun, J., Xing, G., Zhang, C.: Data-driven predictive torque coordination control during mode transition process of hybrid electric veihcles. Appl. Sci. 10(4), 441 (2017)

19. Wang, W., Han, L., Xiang, C., et al.: Synthetical efficiency-based optimization for the power distribution of power-split hybrid electric vehicles. Chin J. Mech. Eng. 27(1), 58-68 (2014) 